\title{
Study of Etiology, Outcome and Limitations of Endoscopic Management of Cerebrospinal Fluid Rhinorrhea
}

\author{
${ }^{1}$ Rohit Verma, ${ }^{2}$ Alok Thakar
}

\begin{abstract}
Aim: The advances in endoscopic sinus surgery have made it the procedure of choice for treatment of cerebrospinal fluid (CSF) rhinorrhea. The objective of this study was to study the etiological factors, the outcome of transnasal endoscopic repair, and limitations of the technique.
\end{abstract}

Materials and methods: Thirty-two cases of CSF rhinorrhea were evaluated. Patients underwent thorough clinicoradiological evaluation followed by transnasal endoscopic repair. Patients were followed up at monthly intervals.

Results: Out of 32 cases, 14 were due to the head injury, 12 were spontaneous, two were iatrogenic, two congenital defects, one was a case of tubercular osteomyelitis and one was idiopathic. CSF leak was successfully plugged in 29 patients. In one patient, the procedure had to be converted to an extracranial external approach. Two patients underwent successful revision endoscopic procedure. One patient was lost to follow-up.

Conclusion: Head injury remains the leading cause of CSF rhinorrhea. The spontaneous leak patients represent a distinct clinical group with a characteristic patient profile, clinical features, and radiology. The results of endoscopic repair are excellent, especially in nonspontaneous cases. We recommend it as the optimum surgical approach for both primary and revisional surgical management of CSF rhinorrhea.

Keywords: Cerebrospinal fluid, Endoscopic, Rhinorrhea, Transnasal.

How to cite this article: Verma R, Thakar A. Study of Etiology, Outcome and Limitations of Endoscopic Management of Cerebrospinal Fluid Rhinorrhea. Clin Rhinol An Int J 2018;11(1):7-14.

Source of support: Nil

Conflict of interest: None

\section{INTRODUCTION}

Cerebrospinal fluid (CSF) rhinorrhea is a rare cause of watery nasal discharge. The origin of CSF may be from any cranial fossae, i.e., anterior, middle or posterior. Although the actual

\footnotetext{
${ }^{1}$ Associate Professor, ${ }^{2}$ Professor

${ }^{1}$ Department of ENT, Dayanand Medical College, Ludhiana, Punjab, India

${ }^{2}$ Department of ENT, All India Institute of Medical Science, New Delhi, India

Corresponding Author: Rohit Verma, Associate Professor, Department of ENT, Dayanand Medical College, Ludhiana, Punjab, India, e-mail: rohitaiims@yahoo.co.in
}

loss of CSF is of no particular consequence, a persistent dural fistula represents a persistent hazard for potentially fatal purulent meningitis. Persistent CSF rhinorrhea is, therefore, an absolute indication for surgical repair of the leak. Until recently, intracranial repair has been the standard method of repair. The disadvantages include greater morbidity, brain retraction, and anosmia. Endoscopic approach allows for a better field of vision, with enhanced illumination and magnification, angled visualization allowing exact localization of leak, the ability to precisely clean the mucosa from the bony defect without significantly increasing the size of the defect, and to accurately position the graft material over the defect. The aim of this study was to evaluate the etiological factors in patients presenting with CSF rhinorrhea and the associations in cases with nontraumatic leaks. We also aimed to evaluate the results of endoscopic repair of CSF leaks. Further, we aimed to specifically pinpoint the reasons for failure and to formulate guidelines for indications and limitations of this technique.

\section{MATERIALS AND METHODS}

The study was conducted on 32 cases of CSF rhinorrhea. The confirmation of nasal fluid to be CSF was done by analyzing it for glucose and protein. The analysis of the nasal fluid for beta 2 transferrin was not done in any of the patients. There was no standard protocol followed with regards to the radiological investigations as the patients were referred from different centers and had radiological studies already done. Various radiological studies done on the patients included noncontrast CT scan of the skull base and paranasal sinuses, CT cisternography, MRI/MR cisternography.

The determination of the etiology was based mainly on history and clinical examination. The diagnosis of spontaneous leaks with benign intracranial hypertension was made on the basis of the patient's symptoms like highpressure type headache, pulsatile tinnitus, patient's clinical profile (middle aged females with a high $\mathrm{BMI}$ ), and radiological demonstration of empty sella on T2 weighted MRI.

\section{Preoperative Medical Treatment}

The patients presenting early with posttraumatic CSF leaks were given a 4-6 weeks trial of conservative management in the form bed rest, head end elevation, avoidance 
of straining. The patients of spontaneous CSF leaks received preoperative medical management in the form of acetazolamide to lower CSF pressure. This was continued postoperatively. Prophylactic antibiotics were not used in any of our patients while they were on conservative treatment, or while awaiting surgery.

\section{Surgery}

All 32 cases were operated under general anesthesia (GA). Hypotensive anesthesia was given whenever it was appropriate. The operative technique has been standardized. For leaks localized on radiology to the fovea ethmoidalis, a complete endoscopic ethmoidectomy and maxillary antrostomy were done for adequate exposure of the skull base defect and the leak. For leaks localized to the cribriform plate, we prefer to go between the nasal septum and the middle turbinate. The leaks in the sphenoid sinus were approached through endoscopic transethmoid approach.

Surgical localization of the leak was guided by the initial preoperative radiological localization. In cases wherein preoperative radiology was not helpful in the localization of the leak, exploration of the entire skull base was undertaken. This involved a complete ipsilateral ethmo-sphenoidectomy to expose the planum sphenoidale, the fovea ethmoidalis, the frontal sinus ostium, the vertical lamella of the cribriform plate, and the horizontal cribriform plate medial to the middle turbinate. In cases where the exposure of the horizontal cribriform plate was deemed inadequate, the middle turbinate was sacrificed by an incision flush with the skull base to improve exposure.

Intrathecal fluorescein was not used in any of the patients. If no active leak was found after exposure of the skull base defect, the anaesthesiologist aided the procedure by procedures designed to increase the intracranial pressure (lowering of the head end; positive pressure ventilation to increase intrathoracic pressure/venous pressure). With this protocol, the leak was localized in all cases and the defect in the skull base and dura visualized in all.

\section{Preparation of the Recipient Bed}

In cases where an encephalocele was found, it was coagulated at its base with bipolar diathermy so as to cause shrinkage and partial reduction of the encephalocele. The preparation of the recipient bed was done by removing several millimeters of mucosa surrounding the bony defect to widely expose the site.

\section{Harvesting the Fascia Graft and Fat}

Initially, we routinely used fascia lata graft, but over the last 4 years we have switched over to the abdominal fascia and abdominal fat graft.

\section{Preparation of the Fat for Injection}

The fat taken into the bowl was diced with the help of a scissor until it was converted into a semisolid form. This diced fat was then taken in a $10 \mathrm{~mL}$ syringe which was then connected to a 14 G or 16 G IV cannula.

\section{Sealing of the Dural Defect and Placement of the Graft}

- Up to 3 layers of closure could be used in individual cases depending on the appropriateness of each. This included sealing of the dural defect. In most instances, this was small, and the defect was sealed by insinuating fat in the dural defect. When appropriate the bath plug technique was used, wherein the fat is first pushed in intradural and is then pulled back by traction on a Vicryl suture attached to the fat. The Vicryl suture is then cut and removed.

- Placement of a graft between the dura and the boneextradural underlay graft. For larger defects, the repair was performed by gently elevating the dura above the bony skull base defect and then placing the fascia graft in an underlay fashion in the epidural space. This technique, however, is inappropriate in situations wherein the dura is tightly adherent to the bony skull base, or is adjacent to vital structures. It was therefore not suitable for leaks from the horizontal part of the cribriform plate, or for leaks from the lateral wall of the sphenoid.

- Overlay fascia graft placed over the bone defect (overlay) - the fascia graft was placed in an overlay fashion over the defect and on the surrounding bone denuded of the mucosa. In cases where it was not possible to place the underlying graft, only single layer if fascia as an overlay graft was used. This repair was then supported with the diced fat injected on to the fascia. The fat was then supported with gel foam and nasal pack.

\section{Sealant/Glue}

Sealant in the form of fibrin glue was used in only five patients.

\section{Postoperative Care}

Postoperatively, all the patients were put on bed rest and received intravenous antibiotics in the form of third-generation cephalosporins for a period of 5-7 days followed by oral antibiotics for a week. Laxatives, cough suppressants, and acetazolamide were routinely prescribed. Postoperative CSF drainage was done using either lumbar drain or repeated lumbar puncture to remove 30-40 mL of CSF daily for 3-5 days. The nasal pack was removed on postoperative day 3 or 4 . Discharge from the hospital 
was at 5-18 postoperative day (mean hospital stay of 8.9 days). Following discharge, all patients continued Acetazolamide for 4 weeks. For spontaneous leaks with benign intracranial hypertension, acetazolamide was given for a period as long as 12 weeks.

\section{Follow-up}

The patients were followed up at monthly intervals. The note was made regarding the duration of follow-up, presence or absence of the leak. Routine otolaryngologic examination and nasal endoscopy were performed to ensure adequate healing of the defect.

\section{OBSERVATIONS AND RESULTS}

In this study, the overall age range was from 5 to 57 years with a mean age of 31.81 years. Fourteen out of 32 cases were males $(43.75 \%)$, while 18 were females $(56.25 \%)$.

\section{Etiology}

Out of 32 cases, 14 (43.8\%) were posttraumatic (head injury), $12(37.5 \%)$ were spontaneous, 2 (6.2\%) were iatrogenic, $2(6.2 \%)$ were congenital, 1 (3.1\%) case was that of skull base tubercular osteomyelitis, and 1 (3.1\%) case was of uncertain etiology (idiopathic). Out of the iatrogenic cases, one case was that of post septoplasty delayed onset leak, while the other was that of a leak occurring intraoperatively during endoscopic sinus surgery for allergic fungal sinusitis.

\section{Body Mass Index $\left(\mathrm{kg} / \mathrm{m}^{2}\right)$}

The BMI in the post-traumatic group ranged from 11.0 to 28.7 with a mean of 21.5. In a spontaneous group, the range was from 21.2 to 38.5 with a mean of 29.7. For others, the range was from 15.0 to 30.6 with a mean of 22.3 .

\section{Meningitis Before Repair}

Eleven (34.4\%) out of 32 patients had a history of developing one or more episodes of meningitis before they presented to us. The total number of episodes of meningitis was 23. The number of episodes of meningitis per

Table 1: Distribution of patients developing meningitis

\begin{tabular}{llll}
\hline & $\begin{array}{l}\text { Number } \\
\text { of patients } \\
\text { developing } \\
\text { meningitis }\end{array}$ & $\begin{array}{l}\text { Total number } \\
\text { of episodes of } \\
\text { meningitis }\end{array}$ & $\begin{array}{l}\text { Risk of } \\
\text { meningitis } \\
\text { per month }\end{array}$ \\
\hline $\begin{array}{l}\text { Post } \\
\text { traumatic }\end{array}$ & $6(42.9 \%)$ & 13 & $2.3 \%$ \\
$\begin{array}{l}\text { Spontaneous } \\
\text { Congenital }\end{array}$ & $1(8.3 \%)$ & 1 & $0.5 \%$ \\
Others & $2(100 \%)$ & 6 & $2.9 \%$ \\
\hline Total & $2(50 \%)$ & 3 & $10.3 \%$ \\
\hline
\end{tabular}

patient ranged from 1 to 5 . The distribution of a number of patients developing meningitis and the total number of episodes as per etiology is depicted in Table 1.

\section{Previous Attempts at Repair}

Two patients had their leak repaired previously before they presented to us. Previous surgery was intracranial in one of these patients. The leak recurred in this case after 4 months. In the second case, history of multiple attempts at repair of the leak was there, including intracranial as well as extracranial endoscopic repair, but these attempts were unsuccessful.

\section{Surgical Procedure}

Cerebrospinal fluid (CSF) leak could be repaired endoscopically in 31 patients. In one patient with a leak from the frontal sinus roof, the procedure was started endoscopically. The defect was exposed endoscopically, but the procedure had to be converted to extracranial external approach for better access to seal the defect. The intracranial procedure was not needed for any case. Additional deviated nasal septum required septoplasty in four cases.

\section{Surgical Site of Leak}

The distribution of site of leak seen during surgery is shown in Table 2.

\section{Etiology versus Site of Leak}

The distribution of the site of the leak for various etiologies is shown in Table 3.

Overall the most common site of leak encountered was horizontal CP (40.6\%), followed by FE (25\%), and lateral lamella of CP (15.6\%).

The size of the bony defect ranged from $4-400 \mathrm{~mm}^{2}$ with a mean of $79.8 \mathrm{~mm}^{2}$ The size of the dural defect varied from pinhole to $10 \mathrm{~mm}$. The dural defect of $10 \mathrm{~mm}$ was seen in only one patient while the size of the dural

Table 2: Distribution of site of leak

\begin{tabular}{lll}
\hline Site of leak & Frequency & Percentage \\
\hline Horizontal CP & 13 & 40.6 \\
CP FE & 1 & 3.1 \\
CP LL & 5 & 15.6 \\
FE & 8 & 25.0 \\
Frontal & 1 & 3.1 \\
Sphenoid lateral & 2 & 6.2 \\
Sphenoid posterior & 1 & 3.1 \\
Sphenoid roof & 1 & 3.1 \\
\hline Total & 32 & 100 \\
\hline
\end{tabular}

$\mathrm{CP}$, cribriform plate; CP FE, junction of cribriform plate and fovea; FE, fovea ethmoidalis; CP LL, lateral lamella of cribriform plate 
Table 3: Site of leak for various etiologies

\begin{tabular}{lllllllll}
\hline & $\begin{array}{l}\text { CP } \\
\text { horizontal }\end{array}$ & CPFE & CPLL & FE & Frontal & $\begin{array}{l}\text { Sphenoid } \\
\text { lateral }\end{array}$ & $\begin{array}{l}\text { Sphenoid } \\
\text { posterior }\end{array}$ & $\begin{array}{l}\text { Sphenoid } \\
\text { roof }\end{array}$ \\
\hline Posttraumatic & 4 & 0 & 3 & 5 & 1 & 0 & 1 & 0 \\
Spontaneous & 6 & 0 & 2 & 1 & 0 & 2 & 0 & 1 \\
Congenital & 2 & 0 & 0 & 0 & 0 & 0 & 0 & 0 \\
latrogenic & 0 & 1 & 0 & 1 & 0 & 0 & 0 & 0 \\
Others & 1 & 0 & 0 & 1 & 0 & 0 & 0 & 0 \\
\hline
\end{tabular}

defect was less than or equal to $5 \mathrm{~mm}$ in rest of the 31 cases. The dural defect was just a pinhole in 13 patients.

\section{Graft Material Used}

The abdominal fascia was used in 21 patients, fascia lata was used in nine patients, and turbinate mucosa was used in one patient. Diced fat was used to support the repair with fascia in 30 patients. Fat was used as 'bath plug' to seal the dural defect in four patients. Fibrin glue was used in five patients. The muscle was used in 2 patients. Middle turbinate bone was used to supplement the repair in one patient.

\section{Placement of the Graft}

Fascia graft was placed in an overlay fashion over the bony defect after making the surrounding area raw in 19 patients. Fascia graft was placed as two layers, i.e., one layer of fascia as an underlay graft between bone and dura, and the second layer of fascia as an overlay graft on a bony defect in 10 patients. Only a single layer of fascia was placed in an underlying manner between bone and dura in one patient. The fat and turbinate mucosa were used to seal the defect in one patient (case of iatrogenic leak encountered during ESS).

\section{Lumbar spinal drainage/repeated lumbar puncture}

Lumbar spinal drainage to drain CSF postoperatively was placed in 19 patients. It was removed on postoperative days 3-5. No complications were seen in patients on CSF drainage except for a low-pressure headache, which was seen in two patients.

\section{Duration of Follow-up}

The duration of the follow-up for 32 patients ranged from 2 to 67 months with a mean of 19.7 months.

\section{Treatment Failure}

Outofa total of 32 patients, therewere 3 treatmentfailuresin the form of recurrence of the leak. The follow-up duration at which the leak recurred in these cases was 1 month, 21 months, and 60 months with a mean of 27.3 months.
2 of these 3 patients with recurrence of leaks underwent revision endonasal extracranial endoscopic repair. The third patient was lost to follow-up. The salient features of the three recurrent cases are summarized in Table 4.

\section{Results of Initial Repair}

When the results of the first repair were plotted against the duration of follow-up, the success rates were seen to be as shown in Graph 1.

Here the success rate was $96.9 \%$ at 6 months as well as 12 months follow-up, $89.4 \%$ at 24 months follow-up, and again $89.4 \%$ at 40 months follow-up. Follow-up beyond 40 months was available for only one patient in which the recurrence occurred at 60 months.

\section{Final Results Inclusive of the Revision Surgery}

Here the success rate was $100 \%$ at 6 months, 12 months, 24 months, and 40 months. The follow-up beyond 40 months was available for two patients out of which the recurrence occurred in one patient at 60 months. So the final success rate at 67 months follow-up was 50\% (Graph 2).

\section{Initial Results by Etiology}

For the nonspontaneous group (post-traumatic, iatrogenic, congenital, and others), the success rate was 100\% till 38 months follow-up. Beyond 38 months, the followup was there for only one patient in whom the recurrence occurred at 60 months. For the spontaneous group, the success rate was $91.7 \%$ till 16 months and $78.6 \%$ till 40 months (Graph 3). Using the log-rank test, the $p$ value for difference in success rates for the two groups for initial repair was 0.12 .

\section{DISCUSSION}

The most common etiology seen was post-traumatic which constituted $43.8 \%$ of the total cases. $37.5 \%$ of the cases were spontaneous CSF leaks. This is in accordance with the literature. ${ }^{1}$

The mean body mass index (BMI in $\mathrm{kg} / \mathrm{m}^{2}$ ) for spontaneous groups was higher (29.7) than that for the traumatic (21.5) and other groups (22.3). Thus, it was found that cases of spontaneous leaks were females in their fourth 
Table 4: Profile of patients with recurrence

\begin{tabular}{llll}
\hline & Recurrence 1 & Recurrence 2 & Recurrence 3 \\
\hline Etiology & Spontaneous & Spontaneous & Posttraumatic \\
\hline Age $($ years $) / \mathrm{sex}$ & $43 / \mathrm{F}$ & $57 / \mathrm{F}$ & $9 / \mathrm{F}$ \\
$\mathrm{BMI}\left(\mathrm{kg} / \mathrm{m}^{2}\right)$ & 33.3 & 34.6 & 11.0 \\
Meningitis episodes prior to & 0 & 1 & 1 \\
initial repair & & & No \\
BIH & Yes & Yes & MRI not done \\
Empty sella & No & Yes & CP, small meningocele \\
Site of leak & Sphenoid lateral & Sphenoid roof & 30 \\
Bony defect $\left(\mathrm{mm}^{2}\right)$ & 35 & 50 & 3 \\
Dural defect $(\mathrm{mm})$ & Pinhole & Pinhole & Moderate \\
Volume of leak & Minimal & Moderate & Fascia lata \\
Graft used & Abdominal fascia & Fascia lata & Overlay \\
Graft placement & Overlay & Overlay & Not documented \\
Site of leak at revision surgery & CP & CP FE & 60 months \\
Total follow-up & 14 months & 67 months & Lost to follow-up \\
Current status & No leak & No leak & \\
\hline
\end{tabular}

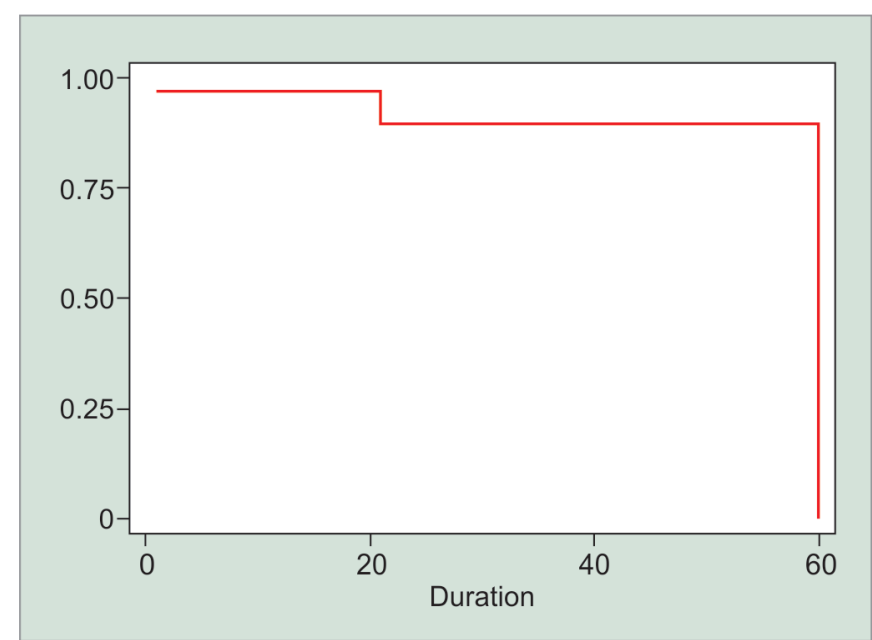

Graph 1: Success rate after first repair

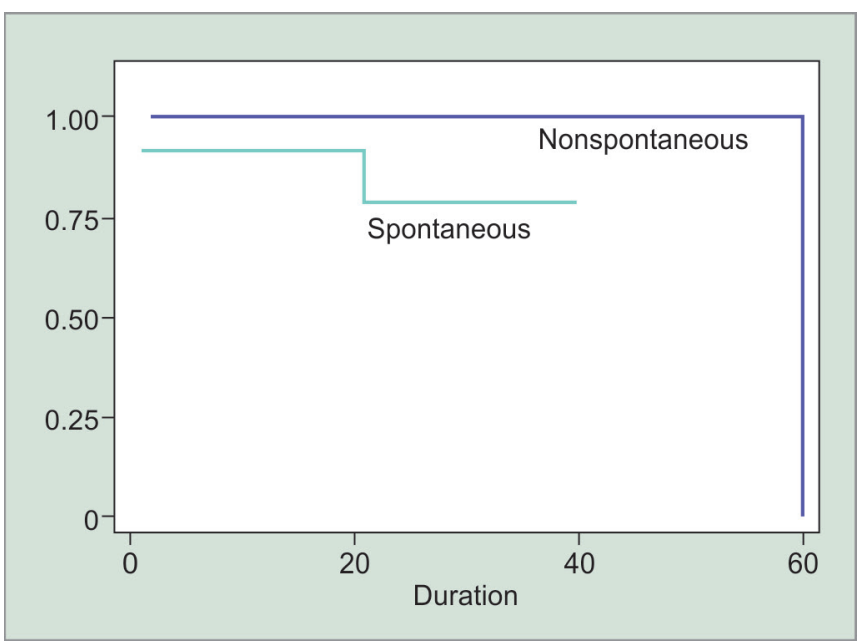

Graph 3: Success rate by etiology

or fifth decade with high BMI. Similar patient profile for spontaneous leaks was observed by Dunn et al. ${ }^{2}$

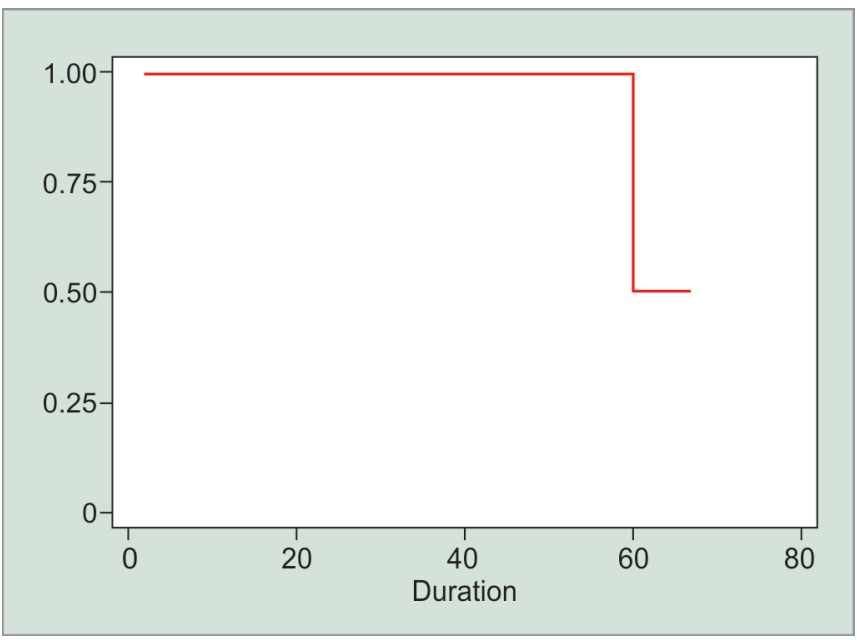

Graph 2: Success rate inclusive of revision surgery

Eleven (34.4\%) patients had a history of meningitis. This is consistent with the reports in the literature that state that the posttraumatic fistulae develop meningitis at some stage in $9-50 \%$ cases. $^{3}$

In literature, there have been studies on the association of spontaneous CSF rhinorrhea and empty sella syndrome (ESS). Gray et al. ${ }^{4}$ advised that ESS should be considered a diagnostic possibility in patients with nontraumatic CSF leaks. In this study, empty sella or partially empty sella on T2 weighted MRI was observed in 5 out of 12 patients in the spontaneous group. None of the patients with other etiologies had an empty sella on MRI. This corroborates with the observations by Schlosser et al. ${ }^{5}$

In this study, the most common site of the leak was a cribriform plate (either horizontal lamina or lateral lamella). This was seen in 18 (56.3\%) of cases. Thirteen patients had a leak at horizontal lamina of the cribriform 
plate while five patients had a leak at the lateral lamella of the cribriform plate. The most common site of the leak in the posttraumatic group was a cribriform plate (horizontal lamina/lateral lamella) followed by fovea ethmoidalis. Park et al. ${ }^{6}$ found the most common site of traumatic fistulae to be fovea ethmoidal and posterior frontal sinus wall, followed by the cribriform plate and sphenoid sinus.

In case of spontaneous leaks, the most common site of the leak in this study was again cribriform plate followed by sphenoid sinus (lateral wall or roof). Ommaya ${ }^{7}$ also reported cribriform plate to be the most common site for nontraumatic leaks. In a study by Kirtane et al., ${ }^{8}$ the most common site of the leak was found to be a cribriform plate $(81.25 \%$, i.e., 184 of 227 patients with unilateral CSF leak) in both posttraumatic as well as spontaneous cases. The salient features of spontaneous and posttraumatic CSF leak patients are summarized in Table 5 .

The preoperative localization of the site of CSF leak was done with radiological studies in the form of CT scan, MRI with/without MR cisternography and CT cisternography. The radiology was excellent to good in CSF leak localization in all but three cases. This included two cases of posttraumatic leaks that had multiple fractures of the skull base and it was not clear which of the fracture sites was actively leaking

Table 5: Salient features of posttraumatic and spontaneous leak patients

\begin{tabular}{|c|c|c|}
\hline & $\begin{array}{l}\text { Spontaneous } \\
(n=12)\end{array}$ & $\begin{array}{l}\text { Posttraumatic } \\
(n=14)\end{array}$ \\
\hline Relative frequency & $37.5 \%$ & $43.8 \%$ \\
\hline Mean age (years) & 24 & 45.7 \\
\hline Males:Females & $0: 12$ & $10: 4$ \\
\hline Mean BMI $\left(\mathrm{kg} / \mathrm{m}^{2}\right)$ & 29.7 & 21.5 \\
\hline Duration of leak (months) & $\begin{array}{l}2-72 \\
\text { (mean 18.2) }\end{array}$ & $\begin{array}{l}1-132 \\
\text { (mean 39.8) }\end{array}$ \\
\hline \multicolumn{3}{|l|}{ Associated symptoms } \\
\hline Headache & $6(50 \%)$ & $8(57.1 \%)$ \\
\hline Anosmia & $2(16.7 \%)$ & $3(21.4 \%)$ \\
\hline Pulsatile tinnitus & $2(16.7 \%)$ & $0(0 \%)$ \\
\hline $\begin{array}{l}\text { Meningitis prior to repair } \\
\text { (risk per month) }\end{array}$ & $0.5 \%$ & $2.3 \%$ \\
\hline Comorbidities & $\begin{array}{l}\text { NIDDM, } \\
\text { hypertension, } \\
\text { bronchial } \\
\text { asthma, etc. }\end{array}$ & $\begin{array}{l}\text { Posttraumatic } \\
\text { seizures }\end{array}$ \\
\hline Empty sella on MRI & 5 & None \\
\hline Most common site of leak & $\begin{array}{l}\mathrm{CP} \\
\text { (horizontal } \\
\text { lamina }=4, \\
\text { lateral } \\
\text { lamella }=3 \text { ) }\end{array}$ & $\begin{array}{l}\mathrm{CP} \\
\text { (horizontal } \\
\text { lamina = 6, } \\
\text { lateral } \\
\text { lamella = 2) }\end{array}$ \\
\hline
\end{tabular}

at the time of presentation. CT cisternography is a useful investigation for such cases if they are having an active leak at the time of the investigation. Another case where the radiology was unable to localize the site of the leak was a case of the spontaneous leak with a small defect in anterior CP. The leak, in this case, was falsely localized to the sphenoid sinus as it was seen filling up with CSF. The scans were done in the supine position in this patient leading to CSF tracking down with gravity and collecting in the sphenoid sinus. This led to the false interpretation of the leak site to be from the sphenoid, thus emphasizing the need to conduct the scans in the prone position.

Connective tissue graft was used in the form of fascia for sealing the CSF leak. Middle turbinate bone was used to seal the defect in only one patient. Many authors ${ }^{9-11}$ have recommended the use of turbinate or septal bone for sealing the defects larger than $0.5 \mathrm{~cm} .{ }^{2}$ However, Kirtane et al., ${ }^{8}$ does not recommend the use of composite grafts. We have also stopped using tissue sealants in the form of fibrin glue. We have devised a novel method in which we use diced fat as the tissue sealant.

Postoperative CSF drainage was used to lower the intracranial pressure, in the form of the indwelling lumbar drain or repeated lumbar puncture for 3-5 days. This is especially relevant for cases of spontaneous leaks with benign intracranial hypertension, where sealing the CSF leak can cause a sudden surge of raised intracranial pressure and can jeopardize the surgical repair.

We also recommend the use of oral acetazolamide in the postoperative period for all patients. For nonspontaneous leaks, it is given for 4 weeks. However, for spontaneous leaks, where the cause is benign intracranial hypertension, we continue acetazolamide for as long as 3 months.

When only the initial repair was considered, the success rate was $96.9 \%$ at 6 months as well as 12 months follow-up. The success rate reduced to $89.4 \%$ at 24 months and continued to be the same till 40 months follow-up.

When the revision surgery was included in the results (revision surgery was performed in two cases), a success rate of $100 \%$ was achieved till 40 months follow-up. The follow-up beyond 40 months was achieved in 2 patients, one of whom failed at 60 months and has since then been lost to follow-up. These results are comparable to the results published by various authors over the past two decades. ${ }^{8-17}$ In various studies, the success rate for endoscopic repair of CSF leaks has varied from $76-100 \%$ after the first attempt and $86-100 \%$ after the second attempt. In a meta-analysis by Hegazy et al., ${ }^{18}$ the endoscopic repair was successful in $90 \%$ of the cases after the first 
attempt, and $97 \%$ after a second attempt. No correlation was found between the size of the bony or dural defect and the outcome of the surgery.

\section{Causes of Failure}

In this study, it was observed that the most common cause of failure of the surgery is unrecognized or unattended to underlying pathology in the form of benign intracranial hypertension. Out of three recurrences seen, two were cases of spontaneous leaks with benign intracranial hypertension. This entity should be suspected in all cases of spontaneous leaks. Equally important is the administration of a medical therapy (acetazolamide) to decrease the intracranial pressure in conjunction with taking these patients up to repair the CSF leak. This has to be continued postoperatively for the appropriate duration in consultation with the neurologist.

Another failure seen in this study was a case of posttraumatic CSF leak with multiple fractures of the skull base. In such cases, it is important to ascertain which of the fracture sites is actively leaking when such a patient presents. In cases where usual radiological techniques (CT/MRI) cannot pinpoint the exact leaking site among the multiple skull-base defects, CT cisternography can be useful in localizing the leak site. If still not localized, surgical exploration of the entire skull base can be undertaken via an endoscopic sphenoethmoidectomy.

\section{Limitation of the Endoscopic Repair}

The only limitation of endoscopic repair of CSF leak that was observed in this study was to seal the defect localized in the roof of the frontal sinus. In one such case encountered by us, although the leak site could be exposed endoscopically, the procedure had to be converted to external approach for better access to seal the defect.

\section{CONCLUSION}

We draw following inferences from the results of this study:

- The most common etiology of CSF rhinorrhea remains head injury.

- The spontaneous leak patients are a distinct clinical group with a characteristic patient profile, clinical features, and radiology.

- The most common site of the leak in posttraumatic as well as spontaneous leaks is cribriform plate.

- The risk of meningitis in untreated CSF leaks is significantly high, thus emphasizing the need for early surgical intervention in cases of persistent leaks.

- The risk of meningitis is much less in spontaneous leak group as compared to other etiologies.
- There is no difference in the risk of meningitis in patients with intermittent or continuous leaks.

- Radiology is good to excellent in the localization of the CSF leak site.

- The results of endonasal endoscopic repair of CSF rhinorrhea continue to be excellent for both primary as well as revision cases. However, further long-term follow-up is required before validating the results of this technique in comparison to the gold standard technique of intracranial repair.

- Spontaneous leaks are a difficult entity to treat and the results of repair are not as good for spontaneous leaks as for other etiologies. The underlying pathology, i.e., raised intracranial pressure, has to be treated in conjunction with subjecting the patient to surgery.

- There is no correlation between the volume of CSF leak, site of leak, or size of the bony or dural defect with the outcome of the surgery.

- Repair of frontal sinus leaks is a limitation of endoscopic technique.

\section{REFERENCES}

1. Beckhardt RN, Setzen M, Carras R. Primary spontaneous CSF rhinorrhea. Otolaryngology Head and Neck Surge 1991; 104:425-432.

2. Dunn CJ, Alaani A, Johnson AP. Study on spontaneous CSF rhinorrhea: its etiology and management. J Laryngol Otol 2005;119:12-15.

3. Leading article: Deaths from bacterial meningitis in 1973. Br Med J 1974;2:453.

4. Gray WC, Salcman M. CSF rhinorrhea associated with empty sella syndrome. Arch Otolaryngol 1980;106:302-305.

5. Schlosser RJ, Bolger WE. Spontaneous nasal CSF leaks and empty sella syndrome: a clinical association. Am J Rhinol 2003;17:91-96.

6. Park J, Strelzow VV, and Friedman WH. Current management of CSF rhinorrhea. Laryngoscope 1983;93:1294-1300.

7. Ommaya AK. Spinal fluid fistulae. Clinical Neurosurgery 1976;23:363-392.

8. Kirtane MV, Gautham K, Upadhyaya SR. Transnasal endoscopic approach for CSF rhinorrhea. Otolaryngol Head Neck Surg 2005;132:208-212.

9. Burns JA, Dodson EE, Gross CW. Transnasal endoscopic repair of cranionasal fistulae: a refined technique with long term follow-up. Laryngoscope 1996;106:1080-1083.

10. Hughes RGM Jones NS, Robertson IJA. The endoscopic treatment of CSF rhinorrhea: the Nottingham experience. J Laryngol Otol 1997;111:125-128.

11. Mao VH, Keane WM, Atkins JP et al. Endoscopic repair of CSF rhinorrhea. Otolaryngol Head Neck Surg 2000;122:56-60.

12. Papay FA, Maggiano H, Dominquez S, Hassenbusch SJ, Levin HL, Lavertu P. Rigid endoscopic repair of PNS CSF fistulas. Laryngoscope 1989;99:1195-1201.

13. Mattox DE, Kennedy DW. Endoscopic management of CSF leaks and encephaloceles. Laryngoscope 1990;100:857-862.

14. Stankiewicz JA. CSF fistula and endoscopic sinus surgery. Laryngoscope 1991;101:250-256. 
15. Dodson EE, Gross CW, Swerdloff JL, et al. Transnasal endoscopic repair of CSF rhinorrhea and skull base defects. Otolaryngol Head Neck Surg 1994;111:600-605.

16. Shick B, Ibing R, Brors D, et al. Long term study of endonasal duraplasty and review of the literature. Ann Otol Rhinol Laryngol 2001;110:142-147.
17. Woodworth BA, Schlosser RJ, Palmer JN. Endoscopic repair of frontal sinus CSF leaks. J Laryngol Otol 2005;119: 709-713.

18. Hegazy HM, Carrau RL, Snyderman CH, Kassam A. Transnasal endoscopic repair of CSF rhinorrhea: a meta-analysis. Laryngoscope 2000;110:1166-1172. 